\title{
Polyethylene Terephthalate (PET) Bottles Waste as Fine Aggregate in Concrete
}

\author{
Altamashuddinkhan Nadimalla, Siti Aliyyah Binti Masjuki, Asmahani Binti Saad, Kamsiah \\ Binti Mohd Ismail, Maisarah Bt Ali
}

\begin{abstract}
Concrete construction industry is one of the major sector utilizing natural resources to produce concrete for building constructions. The rapid increase in building constructions and the demand for natural aggregates has resulted in depletion natural resources at an alarming rate. Uncontrolled mining activity worsens the situation. Thus serious awareness has been taken into consideration, has to be identified as a potential river sand substitution for fine aggregates replacement in concrete. For this review, utilizing recycled material are described as a fine aggregate replacement to river sand, particularly recycled Polyethylene Terephthalate (PET) bottles. Recycled PET Bottles are categorized as nonbiodegradable waste materials which are injurious to health. Recycled PET bottles in concrete are economical and help in reducing disposal problems. Recycled PET bottles are pondered as the best eco-friendly alternative not only for resolving the problem of disposal but as a new construction material for concrete.
\end{abstract}

Keywords-PET bottles, fine aggregate replacement, Split tensile, Compressive strength, Flexural strength

\section{INTRODUCTION}

Over the past few years, It is estimated that roughly 25 billion tonnes of concrete manufactured each year globally. The current concrete construction industries consumed vast amounts of natural aggregates and approximately 2 billion tonnes of Portland Cement. The excessive raw materials consumption potentially release greenhouse gases leading to global warming. Therefore, the need to incorporate recycled materials as a substitution to construction materials are essential to reduce landfill space as well as a shortage of natural resources. Waste materials increase with increasing population and most of these materials are non-degradable. The excessive disposal of non-degradable materials can lead to environmental pollution. To overcome this serious issue, the recycle of non-degradable materials is very substantial.[1] [2][5][13].

Normally $60-80 \%$ of the aggregates used in concrete and it shows a significant function in concrete performance such as, strength, workability, durability and stability. The unwanted materials as an alternative replacement to aggregate can potentially reduce environmental issues on

Revised Manuscript Received on April 12, 2019.

Altamashuddinkhan Nadimalla, Kulliyyah of Engineering, IIUM, Kuala Lumpur, Malaysia. (E-mail: altamashk1987@gmail.com)

Siti Aliyyah Binti Masjuki, Kulliyyah of Engineering, IIUM, Kuala Lumpur, Malaysia. (E-mail: aliyyah@iium.edu.my)

Asmahani Binti Saad, Kulliyyah of Engineering, IIUM, Kuala Lumpur, Malaysia. (E-mail: asmahanisaa@iium.edu.my)

Kamsiah Binti Mohd Ismail, Kulliyyah of Engineering, IIUM, Kuala Lumpur, Malaysia. (E-mail: kamsiahmohdismail@iium.edu.my)

Maisarah Bt Ali, Kulliyyah of Engineering, IIUM, Kuala Lumpur, Malaysia. (E-mail: maisarah@iium.edu.my) lack of natural resources as well as abundant waste disposal. Recently, vast studies have been conducted with regards to construction materials to identify the most suitable waste materials that can be used as aggregates substitution. Amongst all, stone dust, quarry dust, granulated coal ash, recycled Polyethylene Terephthalate (PET) bottles and sheet glass powder were identified as the most commonly used potential materials to support the initiative [3]. Overall, these unwanted materials are suitable to be used as fine aggregate replacements due to their similar physical properties as conventional fine aggregate, sand.

Polyethylene terephthalate (PET) most commonly used material which is mainly obtained from soft-drink as well as drinking bottles and container from packaging food. PET bottles due to its lightweight properties have replaced the glass bottles and because of it is easy handling and storage. Plastic bottles made of PET, which originates a major fraction of domestic wastes. They are considered as nonbiodegradable surplus materials which are injurious to public health. So making use of PET bottles waste in concrete production can be a useful method to get rid of plastics solid waste damage on the environment [4].

\section{REVIEW OF RESEARCH \& RESULTS}

\section{A. Classification of PET bottles}

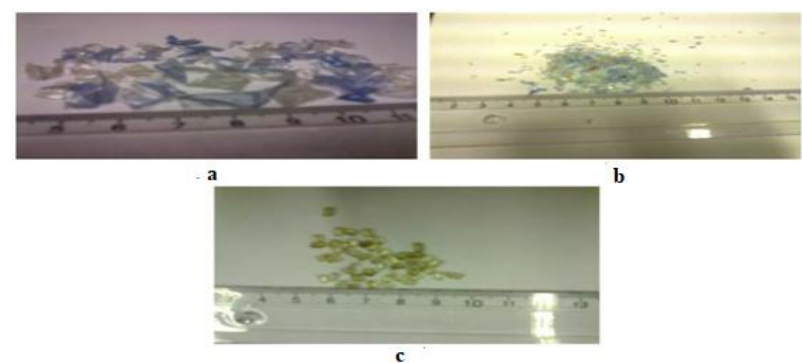

Fig. 1. PET bottles aggregate size classification (a) Coarse flaky (PC); (b) Fine flaky (PF; (c) pellet-shaped (PP) [3]

The shredded fractions of PET bottles aggregate are flaky within two sizes are as follows, coarse (PC) and fine (PF). The heat-treated aggregates is in a spherical shape and is called PP as shown in Figure.1 [3]. Variances in shape, size and texture of PET bottles aggregates transmute the fresh properties of concrete mixes, which conclusively modify the mechanical behavior [3].

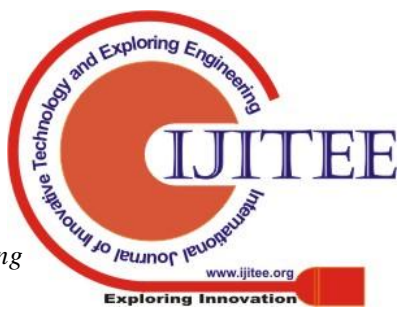


It is generally seen that replacing PET bottles aggregate in a concrete mix initiates a reduction in tensile and compressive strength because of the ineffective bond between the PET bottles aggregate and other materials in concrete. The weak bond around PET bottles aggregate precedes to decrease tensile strength and compressive strength. The use of a PET bottles aggregates be the same as the size of the sand particles at a substitution of $10 \%$ by amount, provided the most satisfactory results[11].

\section{B. Slump test}

The slump of PET bottles aggregate concrete is depend upon numerous factors such as the shape of the aggregate substitution level of aggregates and the water-cement ratio (w/c). There are two comparable interpretations on the workability behavior of concrete having PET bottles aggregate. In various research, a reduced slump of concrete was because of the substitution of various types of PET bottles aggregate in the normal concrete mix was noticed and a rising in PET bottles aggregate reduces the slump of concrete [6][7]. The causes for the reduced slump of the concrete mix was because of angular and sharp edges of PET bottles aggregate [3]. In other few studies because of the round structure of the treated PET bottles aggregate and glassy surface, which reduced the friction between the concrete mix and the PET bottles aggregate and therefore improves the slump of concrete as shown in figure 2 [8].

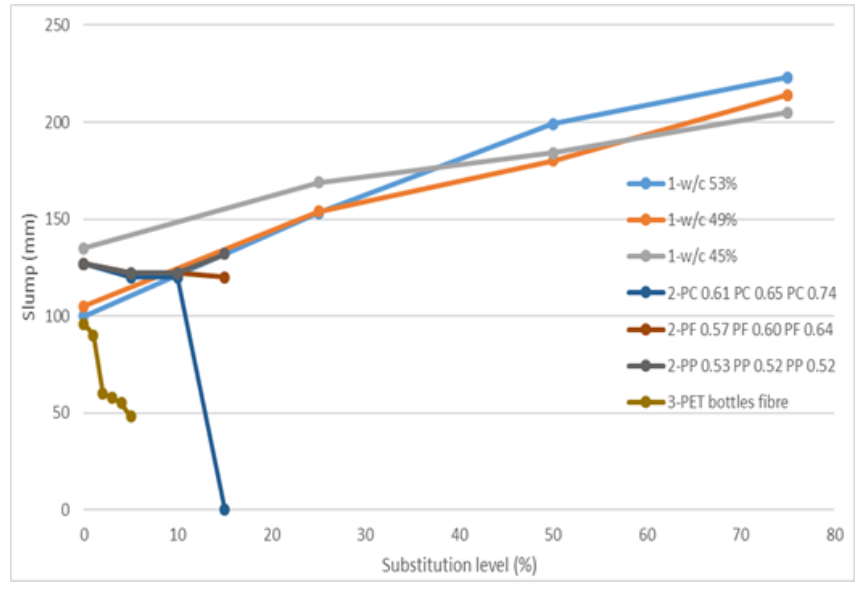

Fig. 1. Slump: 1-[8];2-[3];3-[14]

\section{Hardened Properties of PET Bottles Concrete}

\section{Compressive Strength test}

The concrete compressive strength is an essential property that is systematically investigated in almost all investigation associated to PET bottles aggregate. In all these findings it was initiate that the substitution of PET bottles aggregates reduced the concrete compressive strength [3] [9] [11].

The concrete compressive strength was good up to $5 \%$ to $10 \%$ replacing PET bottles aggregate with sand, and it diminished for $15 \%$ and $20 \%$ substitutions. Thus, replacing the sand with $5 \%$ to $10 \%$ substitution will be serviceable [11].

$2 \%$ substitution of the fine aggregate with PET bottles fibers increased the compressive strength, and it is progressively reduced by $4 \%$ and $6 \%$ substitution. Hence substitution of fine aggregate with $2 \%$ substitution of PET bottles fibre will be acceptable [12].

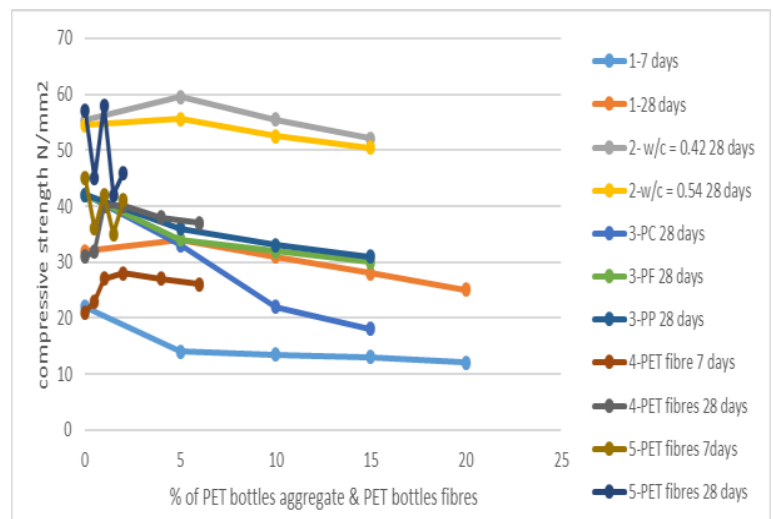

Fig. 2. Compressive Strength test:1- [11];2- [9] ;3-[3]; 4[12]; 5-[10]

\section{Split Tensile Strength Test}

The splitting tensile strength reduction was because of absorbency of concrete initiated by the addition of PET bottles aggregates along with the increase in the w/c ratio as shown in figure 4 [6].

The concrete Split tensile strength was good up to $2 \%$ substitution of the sand with PET bottles aggregate. After this, there was a decrease of $8 \%$ replacements compared with plain concrete for both 7 and 28 curing days as shown in figure 4 [4].

The split tensile strength was good up to $10 \%$ replacing PET bottles aggregate and it is diminished for $15 \%$ to $20 \%$ substitutions. Well graded PET bottle aggregate mixes behaved well in tension when associated to the conventional concrete mix [5].

The split tensile strength increases up to the $2 \%$ substitution of PET bottle fibers and then reduced to some extent with an increase in the substitution PET bottles fibers. The substitution of $2 \%$ of PET bottles fibers is found to be reasonable compared to the other proportions [9].

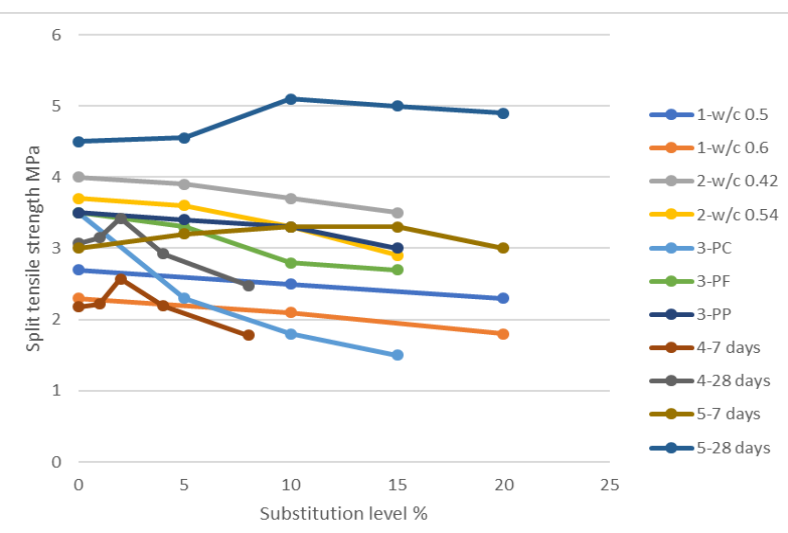

Fig. 3. Split tensile strength 1-[6];2-[9];3-[3];4-[4];5-[11]

\section{Flexural Strength Test}

The capability of the structural component to abstain collapse in deflection is called as flexural strength. The influence of substitution of various forms of PET bottles aggregate and PET bottles fiber on concrete flexural strength of is reviewed below.

Published By: Blue Eyes Intelligence Engineering 
The concrete flexural strength diminishes by means of the volume of PET bottles aggregate increases. In this research, sand was substituted with $5 \%$ to $15 \%$ of PET bottles aggregates. It is observed that as the volume of PET bottles aggregates in concrete raises the modulus of rupture reduces. The remedied PET bottles aggregate (PP) accomplished well as associated to PET bottles coarse aggregate (PC) and PET bottles fine aggregate (PF) [3].

The $2 \%$ of substitution of PET bottles fiber with sand enhanced the modulus of rupture of concrete, which progressively enhanced up to $4 \%$ and continued to stable after $6 \%$. The $4 \%$ of PET bottles fiber replacement with fine aggregate obtain maximum flexural strength compared to the conventional concrete as shown in figure 5 [12].

The flexural strength increased to $10 \%$ replacing of the PET bottles aggregate with fine aggregate, and it slowly diminished by $15 \%$ to $20 \%$ substitutions[11].

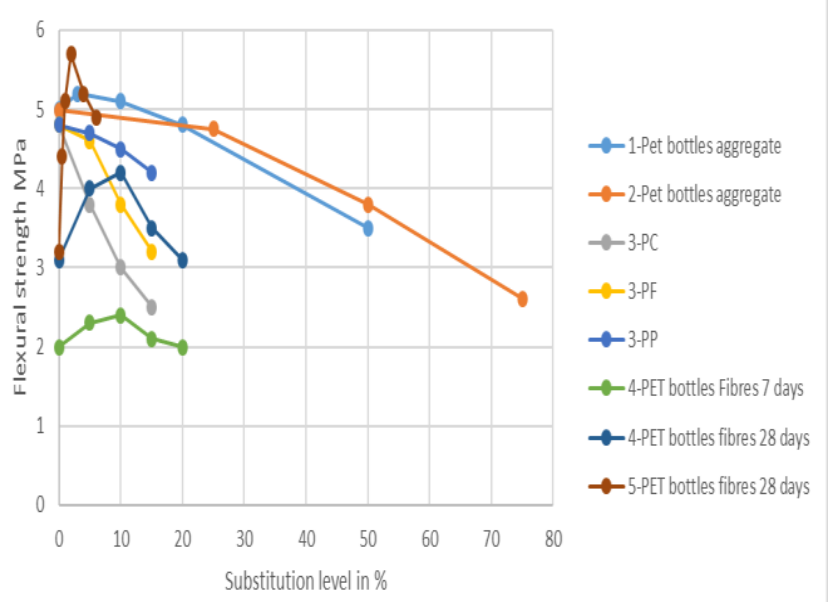

Fig. 5. Flexural strength:1-[14];2-[15];3-[3];4-[11];5-[12]

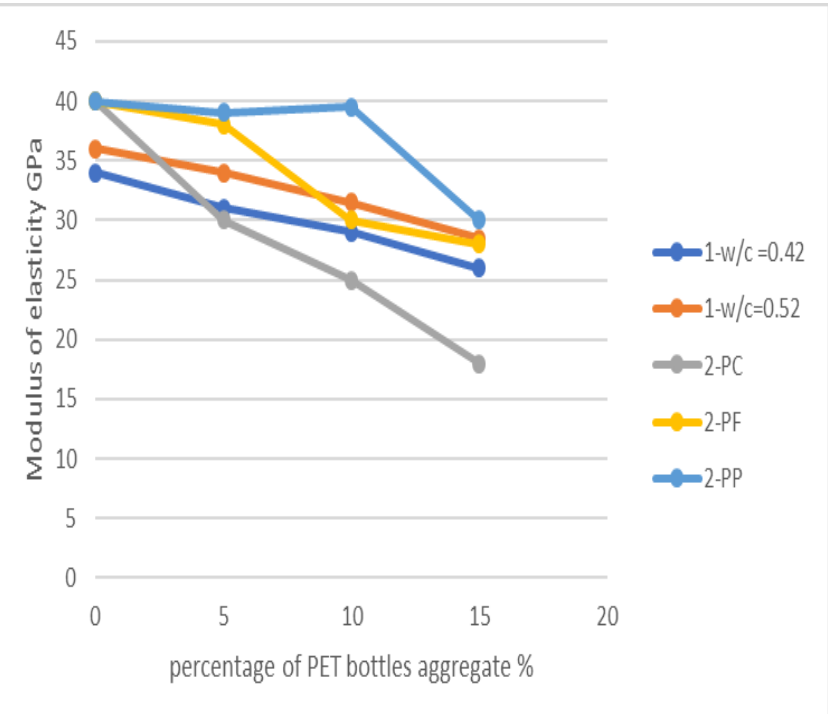

Figure 4: Modulus of elasticity 1- [9]; 2-[3]

\section{Elastic Modulus}

Elastic modulus of concrete mixtures diminished with the addition of PET bottles aggregates. The lessening in elastic modulus may be because of the lesser elastic modulus of PET bottles aggregate flakes [3] [9].

\section{CONCLUSION}

The behavior of hardened and fresh properties of concrete almost depend upon shape and the size of the PET bottles aggregate

- The non-uniform, angular and sharp edges PET bottles aggregates reduce the slump value of concrete mixes.

- The smooth-surface and spherical textured PET bottles aggregate increases the concrete slump value.

- It was identified that the compressive strength enhanced up to $5 \%$ to $10 \%$ substitution of the fine aggregate with PET bottles waste and it is diminished for $15 \%$ and $20 \%$ replacements.

- The flexural and split tensile strength were observed to be improved up to $10 \%$ addition of the fine aggregate with PET bottle aggregate and it is diminished for $15 \%$ and $20 \%$ replacements.

- From the above literature review it is pretended that the suitable amount utilisation of PET Bottles as sand replacements in concrete will improve the physical behavior and performance of recycled material concrete as compared to conventional concrete.

\section{REFERENCES}

1. Salahaldein Alsadey, "Utilization of Plastic Bottle Wastein Concrete," Vol. 1, No. 1, pp. 1-5,2016.

2. S. Shaikh, S. S. Bachhav, and D. Y. Kshirsagar, "Effective Utilisation of Waste Glass in Concrete," vol. 5, no. 12, pp. 14, 2015.

3. N. Saikia and J. De Brito, "Mechanical properties and abrasion behaviour of concrete containing shredded PET bottle waste as a partial substitution of natural aggregate,' Constr. Build. Mater., vol. 52, pp. 236-244, 2014.

4. S. D. A. Shubbar and A. S. Al-shadeedi, "Utilization of Waste ربش سدنهملاو يندملا ليقع حلاص نيدلا يديدشلا سردملا نسوس ءايض دمحا, vol. 8, no. 2, pp. 782-797, 2017.

5. Zainab Hasan Abdulabbas and Shereen Qasim Abd-Alridha, "Evaluation of Using Waste of Bottles in Concrete as Sustainable Construction, vol. 24, pp. 63-69, 2016.

6. C. Albano, N. Camacho, M. Hernández, A. Matheus, and A. Gutiérrez, "Influence of content and particle size of waste pet bottles on concrete behavior at different w/c ratios," Waste Manag., vol. 29, no. 10, pp. 2707-2716, 2009.

7. Foti, D.. Use of recycled waste pet bottles fibers for the reinforcement of concrete. Composite Structures, 96, 396404,2013.

8. Y. Wang, D. Joong, Y. Jic, and M. Lachemi, "Characteristics of mortar and concrete containing fine aggregate manufactured from recycled waste polyethylene terephthalate bottles," Constr. Build. Mater., vol. 23, no. 8, pp. 2829-2835, 2009.

9. E. Rahmani, M. Dehestani, M. H. A. Beygi, H. Allahyari, and I. M. Nikbin, "On the mechanical properties of concrete containing waste PET particles," Constr. Build. Mater., vol. 47, pp. 1302-1308, 2013.

10. S. Shahidan, N. A. Ranle, S. S. M. Zuki, F. S. Khalid, A. R. M. Ridzuan, and F. M. Nazri, "Concrete incorporated with optimum percentages of recycled polyethylene terephthalate (PET) bottle fiber," Int. J. Integr. Eng., vol. 10, no. 1, pp. 1-8, 2018.

11. Mastan Vali N and SS. Asadi, "Pet bottle waste as a supplement to concrete fine aggregate," vol. 8 , no. 1, pp. 558568,2017 
12. K. Ramadevi and R. Manju, "Experimental Investigation on the Properties of Concrete With Plastic PET (Bottle) Fibres as Fine Aggregates," J. Emerg. Technol. Adv. Eng., vol. 2, no. 6, pp. 42-46, 2012.

13. ZarafitIqbal Khan, Er. Sugam Seghal \& Er Sameer Malhotra, "Study of Polyethylene Terephthalate PET Plastic Bottles Fiber in Fly Ash Concrete with Partial Replacement of Fine Aggregates by Iron Slag,”, pp. 275-288, 2018.

14. K. Hannawi, S. Kamali-Bernard, and W. Prince, "Physical and mechanical properties of mortars containing PET and PC waste aggregates," Waste Manag., vol. 30, no. 11, pp. 23122320,2010

15. M. I. Juki et al., "Relationship between Compressive, Splitting Tensile and Flexural Strength of Concrete Containing Granulated Waste Polyethylene Terephthalate (PET) Bottles as Fine Aggregate,” Adv. Mater. Res., vol. 795, no. January, pp. 356-359, 2013. 